\title{
A case of metastatic Xp11.2 translocation renal cell carcinoma successfully managed by cytoreductive nephrectomy followed by axitinib therapy
}

\author{
KOICHI NISHIMURA ${ }^{1}$, TOSHIO TAKAGI ${ }^{1}$, NAOHIRO TODA ${ }^{1}$, TOMOKO YAMAMOTO ${ }^{2}$, \\ TSUNENORI KONDO $^{1}$, HIDEKI ISHIDA ${ }^{1}$, YOJI NAGASHIMA ${ }^{2}$ and KAZUNARI TANABE ${ }^{1}$ \\ Departments of ${ }^{1}$ Urology and ${ }^{2}$ Surgical Pathology, Tokyo Women's Medical University, Tokyo 162-8666, Japan
}

Received October 21, 2016; Accepted December 13, 2016

DOI: $10.3892 / \mathrm{mco} .2017 .1142$

\begin{abstract}
Targeted medications for metastatic adult Xp11.2 translocation renal cell carcinoma (RCC) remain to be identified. We herein report a case of metastatic Xp11.2 translocation RCC controlled with cytoreductive nephrectomy $(\mathrm{CN})$ and axitinib therapy. A 57-year-old woman complained of fatigue and low back pain. Imaging studies revealed a right renal tumor, with multiple lung and mediastinal lymph node metastases. Although the patient received $10 \mathrm{mg}$ axitinib therapy for 5 months at the hospital she was initially admitted to, the size of the primary and metastatic lesions was not reduced. Thus, she was referred to the Tokyo Women's Medical University Hospital (Tokyo, Japan) for further treatment, where she underwent CN. On macroscopic examination, almost the entire kidney was replaced by a yellowish brown tumor $>80 \mathrm{~mm}$ in diameter. Immunohistochemical examination confirmed the diagnosis of Xp11.2 translocation RCC. One month after surgery, axitinib therapy was resumed and the size of the metastatic lesions gradually decreased. These findings suggest that axitinib therapy is effective for adult Xp11.2 translocation RCC.
\end{abstract}

\section{Introduction}

Xp11.2 translocation renal cell carcinoma (RCC) involves fusion between the transcription factor binding to IGHM enhancer 3 (TFE3) in chromosome Xp11.2 and various partners, and was classified as a separate subset of RCCs by the World Health Organization in 2004 (1). According to a published article, $1.6 \%$ of adult RCCs involve Xp11.2 translocation and

Correspondence to: Dr Koichi Nishimura, Department of Urology, Tokyo Women's Medical University, 8-1 Kawada-cho, Shinjuku-ku, Tokyo 162-8666, Japan

E-mail: k.nishimura.uro@gmail.com

Abbreviations: RCC, renal cell carcinoma; $\mathrm{CN}$, cytoreductive nephrectomy

Key words: metastasis, molecular-targeted therapy, renal cell carcinoma, nephrectomy
$15 \%$ of patients aged $<45$ years had translocation RCC (2). Compared with conventional RCC, this type of RCC is mostly diagnosed at an advanced stage, as it exhibits an aggressive course (3-7). However, a systemic therapy for metastatic adult Xp11.2 translocation RCC has not yet been established. We herein report a case of metastatic Xp11.2 translocation RCC that was oncologically controlled with cytoreductive nephrectomy $(\mathrm{CN})$ and axitinib therapy.

\section{Case report}

A 57-year-old woman presented to a local hospital with fatigue and low back pain in October 2014. The laboratory tests revealed high levels of aspartate aminotransferase, alanine aminotransferase and lactate dehydrogenase. Ultrasonography and computed tomography revealed a right renal tumor, $80 \mathrm{~mm}$ in diameter, extending to the renal vein. Multiple lung nodules, lymphadenopathy of the mediastinal lymph nodes and pulmonary hilar lymph nodes were also identified (Fig. 1). The patient was diagnosed with RCC of clinical stage T3aN0M1, with intermediate risk according to the Memorial SloanKettering Cancer Center risk classification (8). Although axitinib treatment was administered for 5 months at the initial hospital, the status of the primary and metastatic lesions remained unchanged. Thus, the patient was referred to the Tokyo Women's Medical University Hospital for further treatment in January 2015. CN was planned, followed by targeted therapy. On macroscopic examination following $\mathrm{CN}$, almost the entire kidney was replaced by a yellowish brown tumor $>80$ $\mathrm{mm}$ in diameter. Histological examination of hematoxylin and eosin-stained sections revealed that the tumor was composed of cells with a voluminous clear cytoplasm and pleomorphic nuclei with prominent nucleoli (Fig. 2A). In addition, TFE3 immunostaining was positive (Fig. 2B). Thus, the pathological diagnosis was Xp11.2 translocation RCC. Axitinib treatment was resumed 1 month after surgery. At 11 months after surgery, follow-up computed tomography revealed that the size of the metastatic lung lesions was decreased by $11 \%$, despite the limited effectiveness of the preoperative axitinib therapy (Fig. 3). Adverse events included grade 2 hypertension, grade 2 digestive symptoms and grade 2 hand-foot syndrome, assessed according to the Common Terminology Criteria 


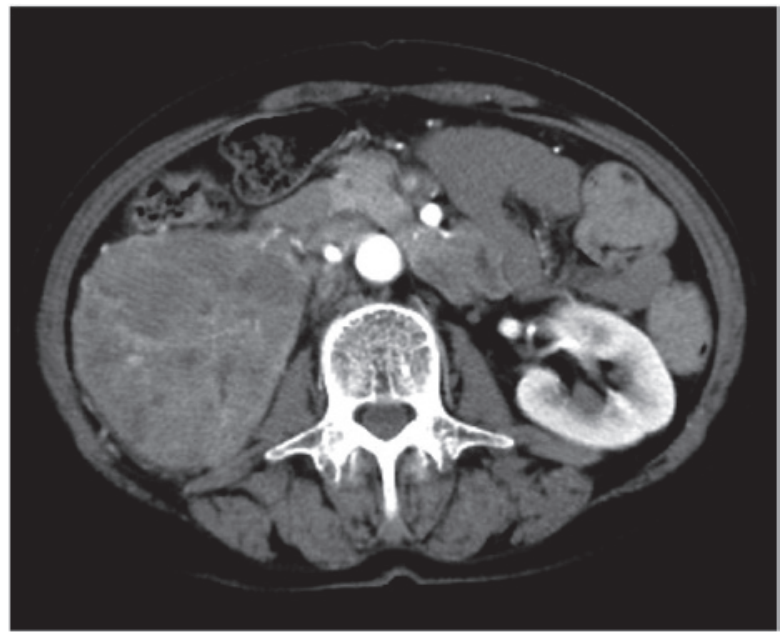

Figure 1. Computed tomography image showing a right renal tumor, $80 \mathrm{~mm}$ in diameter, with a thrombus in the right renal vein.
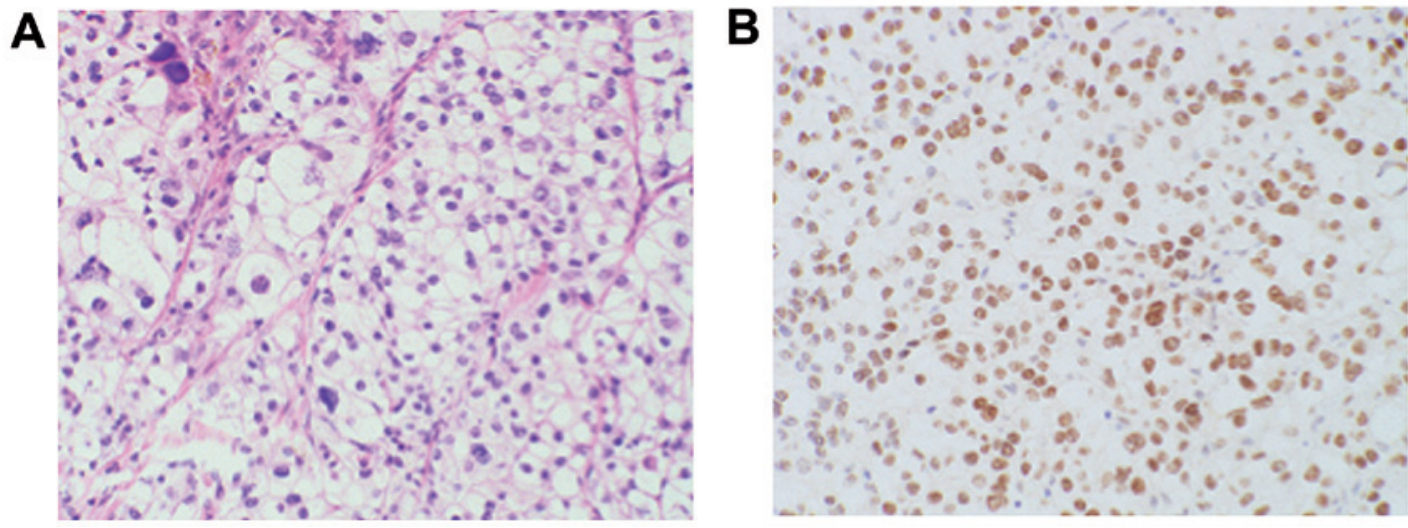

Figure 2. (A) Hematoxylin and eosin staining of a surgical specimen showing that the tumor was composed of cells with a voluminous clear cytoplasm and pleomorphic nuclei with prominent nucleoli (original magnification, x400). (B) Immunostaining for transcription factor binding to IGHM enhancer 3 was positive (original magnification, $\mathrm{x} 400$ ).

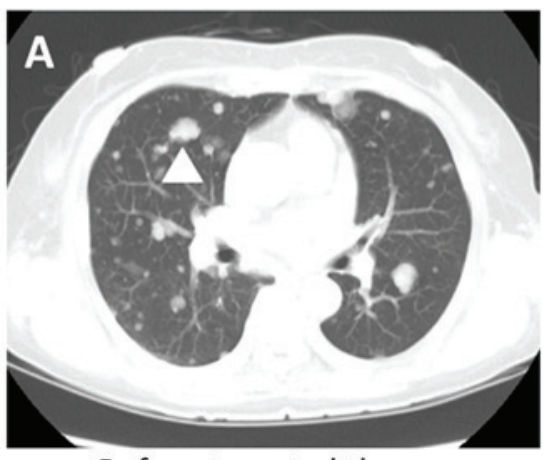

Before targeted therapy

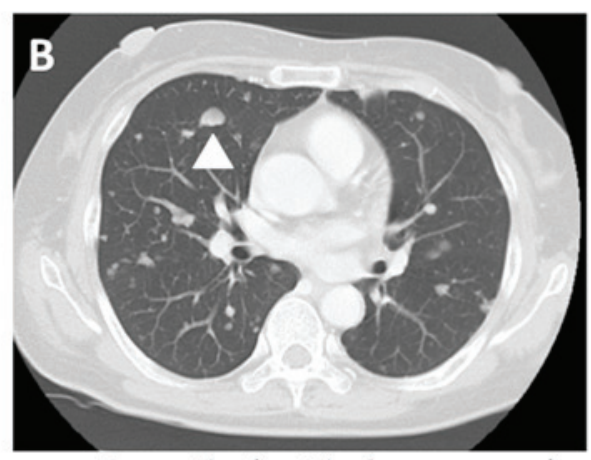

+4 months (just before surgery)

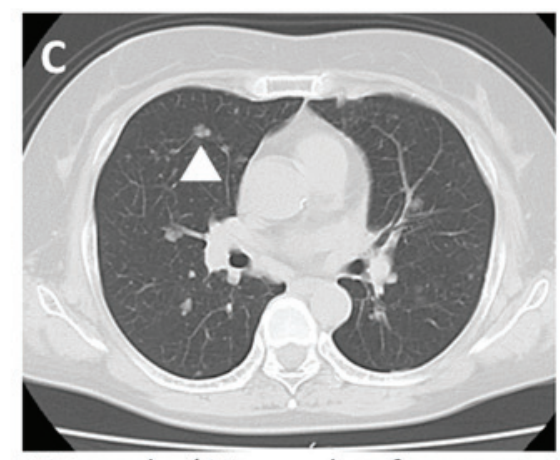

+15 months (11 months after surgery)

Figure 3. (A) Computed tomography revealed lung metastasis prior to the administration of axitinib. (B) The measurable metastatic pulmonary lesion (arrowheads) exhibited a $1 \%$ increase in size at 4 months after the initiation of axitinib (just prior to surgery). (C) The lesion showed a size reduction of $11 \%$ at 15 months after the initiation of axitinib (11 months after surgery).

for Adverse Events, version 4.0 (https://evs.nci.nih.gov/ftp1/ CTCAE/CTCAE_4.03_2010-06-14_QuickReference_5x7.pdf). The patient maintained stable disease for $>12$ months after the surgery and received the last ambulatory treatment in October 2016.

\section{Discussion}

We herein report a case of metastatic Xp11.2 translocation RCC that was oncologically controlled with $\mathrm{CN}$ and axitinib therapy for $>12$ months. In addition, $\mathrm{CN}$ may have 
enhanced the effectiveness of the axitinib therapy in this case. Xp11.2 translocation RCC includes a translocation that activates the MET protein owing to the TFE3 gene on the $\mathrm{X}$ chromosome or the microphthalmia-associated transcription factor (MiTF) on chromosome 6 (6). Several reports investigated the management of metastatic Xp11.2 translocation RCC by immunotherapy $(2,5)$, but the response to this type of therapy was poor. Regarding targeted therapy, previous multicenter retrospective studies of sunitinib reported a median progression-free survival time of 7.1-8.2 months $(9,10)$. One pediatric case of metastatic Xp11.2 translocation RCC was controlled with axitinib therapy (11); however, to the best of our knowledge, reports of adult cases oncologically controlled with axitinib therapy are not available in the literature. The benefit of $\mathrm{CN}$ was evaluated by previous prospective randomized research studies in the cytokine therapy era $(12,13)$. By contrast, the usefulness of $\mathrm{CN}$ in the new era of targeted therapy has not been confirmed in a large randomized trial, although several retrospective studies have demonstrated the effectiveness of $\mathrm{CN}(14,15)$. Heng et al assessed the overall survival benefit of $\mathrm{CN}$ in comparison with targeted therapy without $\mathrm{CN}$ in metastatic RCC (mRCC) patients according to the International Metastatic Renal Cell Carcinoma Database Consortium (IMDC) criteria (16); the authors demonstrated that $\mathrm{CN}$ is beneficial in patients with synchronous $\mathrm{mRCC}$ treated with targeted therapy, even in cases of non-clear cell histology. In addition, they found that the majority of the patients benefited from $\mathrm{CN}$, except for those with $\geq 4$ IMDC risk factors (17). In the present case, axitinib therapy was commenced prior to nephrectomy at the initial hospital, despite the presence of one IMDC risk factor; the time from diagnosis to initial treatment was $<1$ year. Five months of axitinib therapy did not reduce the size of the primary or metastatic lesions. However, $\mathrm{CN}$ followed by axitinib therapy resulted in reduction of the size of the lung and lymph node metastases, suggesting that $\mathrm{CN}$ may enhance the effectiveness of axitinib therapy. However, whether $\mathrm{CN}$ prolongs survival in the targeted era remains unclear and, if so, it should be performed before or after targeted therapy. The results of two ongoing prospective randomized trials, the Clinical Trial to Assess the Importance of Nephrectomy (CARMENA; NCT0093033) and the European Organization for Research and Treating Patients with Metastatic Kidney Cancer trial (SURTIME; NCT01099423), are expected.

\section{References}

1. Armah HB and Parwani AV: Xp11.2 translocation renal cell carcinoma. Arch Pathol Lab Med 134: 124-129, 2010.

2. Komai Y, Fujiwara M, Fujii Y, Mukai H, Yonese J, Kawakami S, Yamamoto S, Migita T, Ishikawa Y, Kurata M, et al: Adult Xp11 translocation renal cell carcinoma diagnosed by cytogenetics and immunohistochemistry. Clin Cancer Res 15: 1170-1176, 2009.

3. Argani P, Olgac S, Tickoo SK, Goldfischer M, Moch H, Chan DY, Eble JN, Bonsib SM, Jimeno M, Lloreta J, et al: Xp11 translocation renal cell carcinoma in adults: Expanded clinical, pathologic, and genetic spectrum. Am J Surg Pathol 31: 1149-1160, 2007.
4. Rais-Bahrami S, Drabick JJ, De Marzo AM, Hicks J, Ho C, Caroe AE and Argani P: Xp11 translocation renal cell carcinoma: Delayed but massive and lethal metastases of a chemotherapyassociated secondary malignancy. Urology 70: 178.e3-178.e6, 2007.

5. Armah HB and Parwani AV: Renal cell carcinoma in a 33-year-old male with an unusual morphology and an aggressive clinical course: Possible Xp11.2 translocation. Pathology 40: 306-308, 2008

6. Tsuda M, Davis IJ, Argani P, Shukla N, McGill GG, Nagai M, Saito T, Laé M, Fisher DE and Ladanyi M: TFE3 fusions activate MET signaling by transcriptional up-regulation, defining another class of tumors as candidates for therapeutic MET inhibition. Cancer Res 67: 919-929, 2007.

7. Camparo P, Vasiliu V, Molinie V, Couturier J, Dykema KJ, Petillo D, Furge KA, Comperat EM, Lae M, Bouvier R, et al: Renal translocation carcinomas: Clinicopathologic, immunohistochemical, and gene expression profiling analysis of 31 cases with a review of the literature. Am J Surg Pathol 32: 656-670, 2008.

8. Motzer RJ, Bacik J, Murphy BA, Russo P and Mazumdar M: Interferon-alfa as a comparative treatment for clinical trials of new therapies against advanced renal cell carcinoma. J Clin Oncol 20: 289-296, 2002.

9. Choueiri TK, Lim ZD, Hirsch MS, Tamboli P, Jonasch E, McDermott DF, Dal Cin P, Corn P, Vaishampayan U, Heng DY, et al: Vascular endothelial growth factor-targeted therapy for the treatment of adult metastatic Xp11.2 translocation renal cell carcinoma. Cancer 116: 5219-5225, 2010.

10. Malouf GG, Camparo P, Oudard S, Schleiermacher G, Theodore C, Rustine A, Dutcher J, Billemont B, Rixe O, Bompas E, et al: Targeted agents in metastatic Xp11 translocation/TFE3 gene fusion renal cell carcinoma (RCC): A report from the Juvenile RCC Network. Ann Oncol 21: 1834-1838, 2010.

11. Sudour-Bonnange H, Leroy X, Chauvet MP, Classe M, Robin PM and Leblond P: Cutaneous metastases during an aggressive course of Xp11.2 translocation renal cell carcinoma in a teenager. Pediatr Blood Cancer 61: 1698-1700, 2014.

12. Flanigan RC, Salmon SE, Blumenstein BA, Bearman SI, Roy V, McGrath PC, Caton JR Jr, Munshi N and Crawford ED: Nephrectomy followed by interferon alfa-2b compared with interferon alfa-2b alone for metastatic renal-cell cancer. N Engl J Med 345: 1655-1659, 2001.

13. Mickisch GH, Garin A, van Poppel H, de Prijck L and Sylvester R; European Organisation for Research and Treatment of Cancer (EORTC) Genitourinary Group: Radical nephrectomy plus interferon-alfa-based immunotherapy compared with interferon alfa alone in metastatic renal-cell carcinoma: A randomised trial. Lancet 358: 966-970, 2001.

14. Choueiri TK, Xie W, Kollmannsberger C, North S, Knox JJ, Lampard JG, McDermott DF, Rini BI and Heng DY: The impact of cytoreductive nephrectomy on survival of patients with metastatic renal cell carcinoma receiving vascular endothelial growth factor targeted therapy. J Urol 185: 60-66, 2011.

15. Conti SL, Thomas IC, Hagedorn JC, Chung BI, Chertow GM, Wagner TH, Brooks JD, Srinivas S and Leppert JT: Utilization of cytoreductive nephrectomy and patient survival in the targeted therapy era. Int J Cancer 134: 2245-2252, 2014.

16. Heng DY, Xie W, Regan MM, Warren MA, Golshayan AR, Sahi C, Eigl BJ, Ruether JD, Cheng T, North S, et al: Prognostic factors for overall survival in patients with metastatic renal cell carcinoma treated with vascular endothelial growth factortargeted agents: Results from a large, multicenter study. J Clin Oncol 27: 5794-5799, 2009

17. Heng DY, Wells JC, Rini BI, Beuselinck B, Lee JL, Knox JJ, Bjarnason GA, Pal SK, Kollmannsberger CK, Yuasa T, et al: Cytoreductive nephrectomy in patients with synchronous metastases from renal cell carcinoma: Results from the International Metastatic Renal Cell Carcinoma Database Consortium. Eur Urol 66: 704-710, 2014. 